OPEN ACCESS

Edited by: Sara Marchiani,

University of Florence, Italy

Reviewed by:

Alessandro Genazzani, University of Modena and Reggio

Emilia, Italy

Settimio D'Andrea,

University of L'Aquila, Italy

${ }^{*}$ Correspondence:

Nanwei Tong

tongnw@scu.edu.cn

${ }^{\dagger}$ These authors have contributed equally to this work

Specialty section: This article was submitted to

Reproduction,

a section of the journal

Frontiers in Endocrinology

Received: 24 January 2021 Accepted: 15 March 2021

Published: 30 March 2021

Citation:

Liu Y, Li J, Yan Z, Liu D, Ma J and Tong N (2021) Improvement of Insulin

Sensitivity Increases Pregnancy Rate in Infertile PCOS Women: A Systemic Review.

Front. Endocrinol. 12:657889. doi: 10.3389/fendo.2021.657889

\section{Improvement of Insulin Sensitivity Increases Pregnancy Rate in Infertile PCOS Women: A Systemic Review}

\author{
Yuqi Liu ${ }^{1,2 \dagger}$, Juan $\mathrm{Li}^{1,2 \dagger}$, Zhe Yan ${ }^{1,2 \dagger}$, Dan Liu ${ }^{3}$, Jinfang $\mathrm{Ma}^{1,2}$ and Nanwei Tong ${ }^{1,2 *}$ \\ ${ }^{1}$ Department of Endocrinology and Metabolism, West China Hospital of Sichuan University, Chengdu, China, 2 Laboratory of \\ Diabetes and Islet Transplantation Research, Center for Diabetes and Metabolism Research, West China Hospital of Sichuan \\ University, Chengdu, China, ${ }^{3}$ Department of Obstetrics and Gynecology, Nantong Rich Hospital of Nantong University, \\ Nantong, China
}

Background: Polycystic ovary syndrome (PCOS) is the most common cause of infertility in reproductive-age women. Insulin increases steroidogenesis, deranges granulosa cell differentiation, and affects follicle growth. However, results from randomized control trials (RCTs) were heterogeneous, and little strong evidence associated actual achievement of insulin sensitivity (IS) improvement with reproductive outcomes.

Objectives: To identify evidence of the reproductive benefit of IS improvement in infertile PCOS women by analyzing eligible RCTs.

Search Strategy: Different search strategies with unlimited keywords, including treatment, therapy, intervention, polycystic ovary syndrome/PCOS, insulin resistance, pregnancy, conceive, live birth, and randomized controlled trials/RCT were used in databases including Pubmed, Embase, and Web of Science to November 20th, 2021.

Data Collection and Analysis: Two authors independently abstracted study details and assessed study quality.

Main Results: Ten RCTs that covered different races and met the inclusion criteria were included for analysis and discussion. Clinical pregnancy rate was increased in infertile PCOS women when they had significant improvement of IS after treatment regardless of the various interventions (non-surgical). The benefits of IS improvement appeared superior in PCOS women without severe obesity. The effect of IS improvement on pregnancy rate was independent of the change of BMl.

Conclusions: Nonsurgical therapeutic strategies that promote superior IS improvement may aid infertile PCOS women to increase their possibility of successful pregnancy regardless of the various interventions. The improvement of IS might be more important than the reduction of BMI in the improvement of pregnancy rate in infertile PCOS women.

Keywords: polycystic ovary syndrome (PCOS), insulin sensitivity, review - systematic, randomized controlled trials (RCT), insulin sensitizers 


\section{INTRODUCTION}

Polycystic ovary syndrome (PCOS) is the most common endocrine disease in reproductive-age women, characterized by hyperandrogenism and olig-anovulation. It is considered a metabolic disorder because it is associated with high rates of insulin resistance (IR), dyslipidemia, obesity, and other metabolic abnormalities. The prevalence of PCOS can reach $18 \%$ in reproductive-age women (1) and those with PCOS have a higher risk of infertility and other health issues (2).

Depending on the pregnancy needs of individuals, therapies for women with PCOS differ. For women who do not desire conception, the aim of treatment is to improve symptoms including acne, hirsutism, and menstrual disorder. Regarding adult infertile women with PCOS, achieving successful pregnancy and live birth are the primary objectives. In PCOS patients with oligo-anovulation, the first-line ovulation induction agents are clomiphene citrate (CC), letrozole (LZ), and metformin (3). CC is an antiestrogen, nonsteroidal compound that can induce ovulation in anovulatory women (4). LZ is an aromatase inhibitor that inhibits the conversion of adrenal androgens to estrogens. It is generally employed for breast cancer therapy (5), and has been found to function as an ovulation induction agent. Metformin, a first-line drug recommended by guidelines for the treatment of diabetes (6), was shown to induce ovulation and improve pregnancy rate in infertile women with $\operatorname{PCOS}(7,8)$, although not as effectively as CC, according to a meta-analysis (9).

The mechanism underlying metformin's effects in PCOS women remains unclear. Metformin improves insulin sensitivity (IS) in the liver and peripheral tissues, which may represent the mechanism explaining its effect in improving pregnancy in PCOS women. The prevalence of IR was reported as $44 \%-70 \%$ in women with PCOS when assessed by surrogate markers (10). PCOS has a multifactorial etiology including intra-uterine, genetic and environmental factors. Familial aggregation studies indicated that PCOS is an inherited disorder and gene variants associated with IR have been demonstrated in PCOS patients. And intra-uterine growth restriction (IUGR) and small for gestational age (SGA) might cause excess glucocorticoids which increased the risk of obesity and hyperinsulinemia during childhood and finally contributed to developing insulin resistance in PCOS women (11). Supraphysiological doses of insulin were found to increase steroidogenesis, derange granulosa cell differentiation, and affect follicle growth (12). However, evidence regarding reproductive outcomes of insulin-sensitizing drugs in PCOS was inconsistent (13) and few analyses focused on actual changes in IS after treatment, which reflects whether these drugs achieve improvement of IR in PCOS women. In another word, the inconsistencies may have been because of failure to achieve improvement of IS. Additionally, some randomized control trials (RCTs) observed beneficial effects of CC and other nondiabetic drugs on IS and also on clinical pregnancy rate $(14,15)$. Taken together, these observations suggest achieving improvement of IS may be the actual factor that promotes an increased rate of pregnancy.
In this review, we summarized data from RCTs that reported post-treatment changes in IS, with the objective of analyzing the correlation between improvement of IS and pregnancy rate in infertile women with PCOS who underwent various nonsurgical interventions, and exploring the reproductive outcomes of insulinsensitizers, such as pioglitazone and exenatide, in PCOS women.

\section{METHODS}

\section{Systematic Review Methodology}

The systematic review was conducted according to the guidelines from PRISMA. We searched electronic databases, including MEDLINE from PubMed, Embase, and Web of Science with different search strategies and no limiting keywords, including treatment, therapy, intervention, polycystic ovary syndrome/ PCOS, insulin resistance, pregnancy, conceive, live birth, and randomized controlled trials/RCT, to November 20, 2020.

Articles were screened by title and abstract. We established the following inclusion/exclusion criteria according to PICOS. 1) Population $(\mathrm{P})$ : reproductive-age women who were infertile because of PCOS rather than other reproductive diseases, and who were not complicated with diabetes or other endocrine disorders. 2) Interventions (I): administration of various reasonable nonsurgical interventions including lifestyle modification, monotherapies, and combined therapies was acceptable. Studies that used assisted reproductive technology or any surgical interventions were excluded. However, at least one parameter pertaining to IS (fasting blood glucose/insulin ratio, insulin sensitivity index, homeostasis model assessment of insulin resistance (HOMA-IR)) was reported before and after treatment. 3) Comparison/control (C): All head-to-head and placebocontrolled RCT were included. 4) Outcomes (O): clinical pregnancy rate and/or live birth rate. 5) Study (S): randomized controlled trials. 6) Additional inclusion/exclusion criteria: To assess IR, baseline fasting blood glucose in the different treatment groups of the included studies was not significantly different. And only Englishlanguage literature was included due to the language barrier.

To include as many relevant clinical trials as possible and without bias, the criteria did not limit treatment duration or sample size. The effects of treatment duration and sample size will be discussed.

Two authors independently abstracted study details and assessed the quality of RCTs in a blinded fashion.

\section{Definition of Insulin Sensitivity and its Improvement After Treatment}

Studies evaluated IS or IR according to different surrogate parameters, including fasting blood glucose/fasting serum insulin ratio, insulin sensitivity index, and HOMA-IR. Although some RCTs reported insulin levels (14-21) before and after treatment, and blood glucose levels, they did not report parameters that reflect IS or IR. Therefore, these trials were excluded from this review.

Each included trial reported whether there was a significant change in the IS parameter before and after treatment, and 
whether it was significantly different between the groups in the trial. The group with significantly increased insulin sensitivity index or reduced HOMA-IR compared with other groups in the same trial was considered to have achieved an improvement of IS. Because of the lack of uniformity in the units of measurement of IS criteria, comparisons were only conducted within a single trial, and could not be conducted with meta-analysis.

\section{Criteria for Overweight and Obesity Among Different Races}

Owing to differences in race, diagnostic criteria for overweight and obesity differ. In America and most Western countries, BMI between 25.0 and 29.9 is considered overweight, BMI $>30.0$ is obese, and $\mathrm{BMI} \geq 35.0$ is considered severely obese (22). However, in Asian populations, BMI between 23.0-27.5 is overweight, $\mathrm{BMI}>27.5$ is obese, and $\mathrm{BMI} \geq 32.5$ is severely obese (23). In this review, we followed the above criteria and classified PCOS women from the included trials as overweight, obese, or severely obese according to race.

\section{Assessment for Quality of RCTs}

The included RCTs were evaluated for quality by using the Cochrane Risk of Bias tool with RevMan 5.4. The assessment consists of seven aspects: random sequence generation, allocation concealment, blinding of participants and personnel, blinding of outcome assessment, incomplete outcome data, selective outcome reporting, and other bias.

\section{RESULTS}

The preliminary search identified 959 unique citations. After screening on title and abstract, 101 eligible studies were identified by full text. In total, 10 studies were included in the final selection (Figure 1).

Ten RCTs from seven countries that covered different races and met the inclusion criteria were included for analysis (24-33). Sample sizes of included RCTs ranged from 25 to 626 (Table 1).

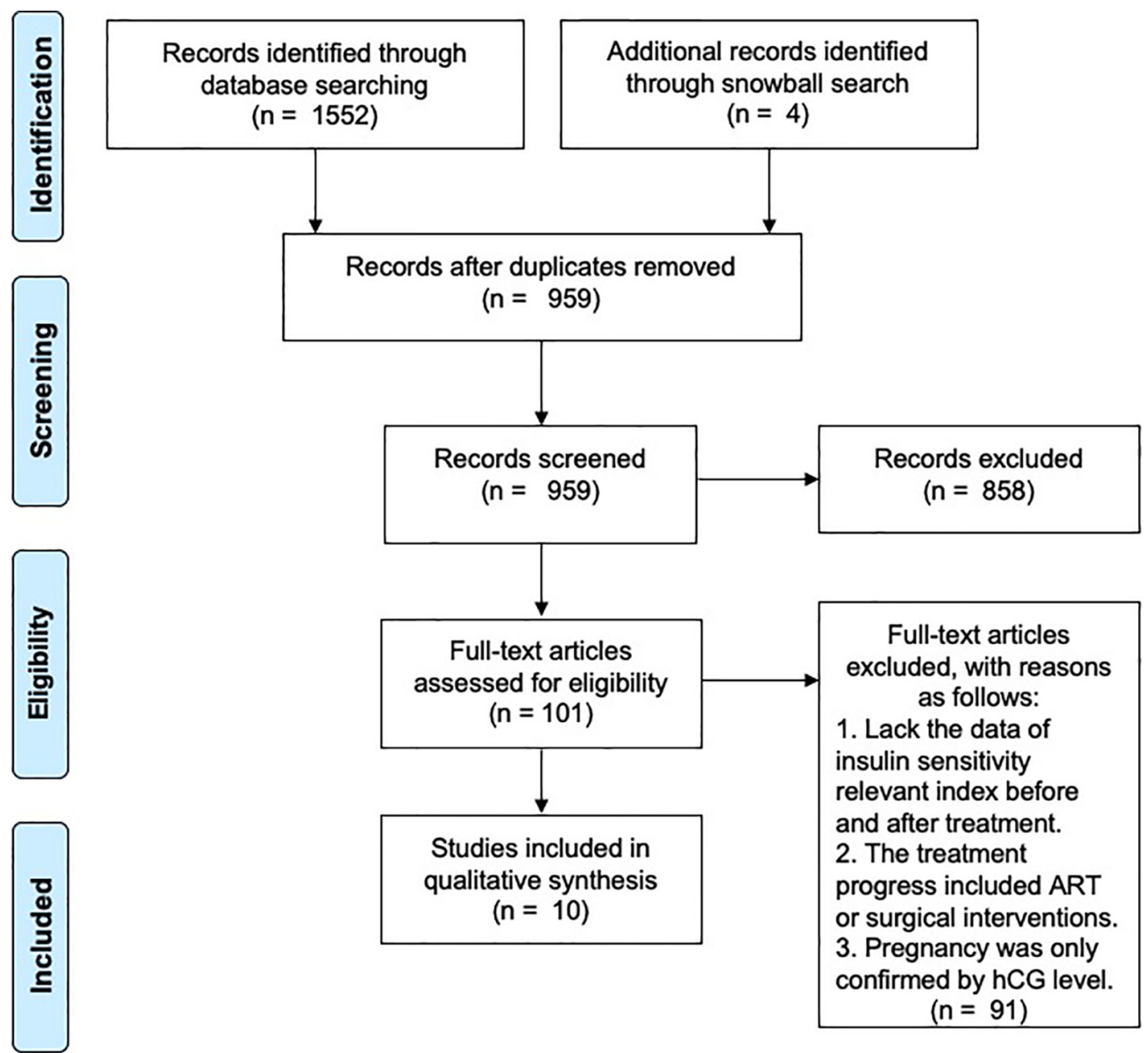

FIGURE 1 | Flow chart showing literature search and study selection. 
TABLE 1 | The sample size, treatment duration, the formula and units of the IS parameters, and the basic condition of subjects in the included RCTs.

\begin{tabular}{|c|c|c|c|c|c|c|c|c|c|}
\hline $\begin{array}{l}\text { Trial } \\
\text { No. }\end{array}$ & Study & $\begin{array}{l}\text { Intervention Group (Subjects } \\
\text { number in each group) }\end{array}$ & $\begin{array}{l}\text { Sample } \\
\text { size }\end{array}$ & $\begin{array}{l}\text { Treatment } \\
\text { Duration }\end{array}$ & $\begin{array}{l}\text { CC resistant } \\
\text { or not }\end{array}$ & $\begin{array}{l}\text { BMI before } \\
\text { treatment }\end{array}$ & $\begin{array}{c}\text { Classification } \\
\text { according to } \mathrm{BMI}^{1}\end{array}$ & $\begin{array}{l}\text { Parameter of } \\
\text { IS }\end{array}$ & $\begin{array}{l}\text { The formula and Unit of the } \\
\text { Parameter that reflects IS }\end{array}$ \\
\hline \multirow[t]{2}{*}{1} & Wang et al. (31) & Metf+CC (N=33) & 78 & $\begin{array}{l}\text { up to } 6 \\
\text { months }\end{array}$ & unknown & $25.74 \pm 6.37$ & Over weight & HOMA-IR & $\begin{array}{l}\mathrm{FPG}(\mathrm{mmol} / \mathrm{L}) \times \mathrm{FINS}(\mathrm{mlU} / \mathrm{L}) \\
/ 22.5\end{array}$ \\
\hline & & Exenatide+CC $(\mathrm{N}=45)$ & & & & $26.26 \pm 5.71$ & & & \\
\hline \multirow[t]{2}{*}{2} & Agrawal et al. (24) & Metformin+CC $(\mathrm{N}=60)$ & 120 & 6 months & unknown & $27.38 \pm 3.92$ & Over weight & HOMA-IR & $\mathrm{mmol} / \mathrm{L}$ \\
\hline & & Metformin+MYO+CC (N=60) & & & & $27.71 \pm 3.60$ & & & \\
\hline \multirow[t]{2}{*}{3} & $\begin{array}{l}\text { Ortega-González et al. } \\
\text { (30) }\end{array}$ & Metformin $(\mathrm{N}=18)$ & 47 & 6 months & unknown & $34.1 \pm 1.6$ & Obese & HOMA-IR & $\begin{array}{l}\mathrm{FPG}(\mathrm{mmol} / \mathrm{L}) \times \mathrm{FINS}(\mu \mathrm{IU} / \mathrm{ml}) \\
/ 22.5\end{array}$ \\
\hline & & Pioglitazone ( $N=17$ ) & & & & $32.2 \pm 1.0$ & & & \\
\hline \multirow[t]{2}{*}{4} & Liu et al. (29) & 24w Metf $(\mathrm{N}=80)$ & 158 & 24 weeks & unknown & $28.29 \pm 1.86$ & Obese & HOMA-IR & $\begin{array}{l}\mathrm{FPG}(\mathrm{mmol} / \mathrm{L}) \times \mathrm{FINS}(\mathrm{mlU} / \mathrm{L}) \\
/ 22.5\end{array}$ \\
\hline & & $\begin{array}{l}\text { 12w Exenatide switch to } 12 \mathrm{w} \text { Metf } \\
(\mathrm{N}=78)\end{array}$ & & & & $29.16 \pm 3.11$ & & & \\
\hline \multirow[t]{2}{*}{5} & $\begin{array}{l}\text { El Sharkwy and Sharaf } \\
\text { El-Din (33) }\end{array}$ & Metf+CC (N=136) & 274 & 3 months & CC-resistant & $34.4 \pm 3.4$ & Severe Obese & HOMA-IR & $\begin{array}{l}\mathrm{FPG}(\mathrm{mmol} / \mathrm{L}) \times \mathrm{FINS}(\mathrm{mlU} / \mathrm{L}) \\
/ 22.5\end{array}$ \\
\hline & & Metf+CC+L-carnitine (N=138) & & & & $35.5 \pm 3.2$ & & & \\
\hline \multirow[t]{3}{*}{6} & Legro et al. (27) & Metformin $(N=208)$ & 626 & $\begin{array}{l}\text { up to } 6 \\
\text { months }\end{array}$ & unknown & $35.6 \pm 8.5$ & Severe obese & $\begin{array}{l}\text { Change in } \\
\text { HOMA-IR }\end{array}$ & FPG $(\mathrm{mg} / \mathrm{dll}) \times \mathrm{FINS}(\mu \mathrm{U} / \mathrm{ml}) / 405$ \\
\hline & & $C C(N=209)$ & & & & $36.0 \pm 8.9$ & & & \\
\hline & & Metformin+CC (N=209) & & & & $34.2 \pm 8.4$ & & & \\
\hline \multirow[t]{2}{*}{7} & Karimzadeh et al. (26) & Metformin $(N=100)$ & 200 & 3 months & unknown & $28.80 \pm 3.18$ & Over weight & FPG/Insulin & The units were not reported \\
\hline & & Placebo $(\mathrm{N}=100)$ & & & & $29.49 \pm 4.75$ & & & \\
\hline \multirow[t]{2}{*}{8} & Yarali et al. (32) & Metformin $(\mathrm{N}=10)$ & 25 & 6 weeks & CC-resistant & $28.6 \pm 4.0$ & Over weight & FPG/Insulin & $\mathrm{FPG}(\mathrm{mmol} / \mathrm{L}) / \mathrm{FINS}(\mathrm{pmol} / \mathrm{L})$ \\
\hline & & Placebo $(N=15)$ & & & & $29.6 \pm 4.8$ & & & \\
\hline \multirow[t]{2}{*}{9} & George et al. (25) & Metf $+\mathrm{CC}(\mathrm{N}=30)$ & 60 & 6 months & CC-resistant & $25.7 \pm 3.9$ & Over weight & FPG/insulin & $\mathrm{FPG}(\mathrm{mg} / \mathrm{dl}) / \mathrm{FINS}(\mu \mathrm{lU} / \mathrm{ml})$ \\
\hline & & $\mathrm{hMG}(\mathrm{N}=30)$ & & & & $25.9 \pm 2.9$ & & & \\
\hline \multirow[t]{3}{*}{10} & Legro et al. (28) & Lifestyle modification ( $\mathrm{N}=50$ ) & 149 & 16 weeks & unknown & $35.1 \pm 4.6$ & Severe obese & insulin & 10,000/square root of (FPG x \\
\hline & & OCPs $(N=49)$ & & & & $35.1 \pm 4.2$ & & sensitivity & FINS) $\times$ (mean glucose $\times$ mean \\
\hline & & Combination $(\mathrm{N}=50)$ & & & & $35.5 \pm 4.4$ & & index & insulin during OGTT) \\
\hline
\end{tabular}

1. The Asian criteria of overweight is BMI between 23-27.5, obesity is $B M I>27.5$, and severe obesity is $B M I>=32.5$.

BMI, Body mass index; CC, clomiphene citreate; Mett, Metformin; MYO, myoinositol; hMG, human menopausal gonadotropin; OCPs, Oral contraceptive pills; HOMA-IR, Homeostatic Model Assessment of insulin resistance; IS, Insulin sensitivity; FPG, Fasting Plasma Glucose; FINS, Fasting Insulin; OGTT, Oral Glucose Tolerance Test; RCT, Randomized Controlled Trial. 
To avoid bias, we included RCTs with small sample sizes, the impact of which is discussed below.

Five RCTs used the HOMA-IR index as the parameter for evaluating IS (Trial No.1-6 in Tables) (24, 27, 29-31, 33), whereby larger value indicates more IR (less IS), whereas three studies reported the fasting plasma glucose (FPG)/insulin (INS) ratio (Trial No.7-9) $(25,26,32)$, whereby larger value indicates improved IS. Only Legro et al. (Trial No.10 in Tables) used the insulin sensitivity index (28) (Table 1). Although the various parameters and units of measurement employed by each study made it difficult to compare IS status among different trials, changes in IS could be compared within a given trial (Table 1).

Only four trials among the included RCTs reported live birth rate (Trial No.2, 3, 6, 10) $(24,27,28,30)$, although all ten reported clinical pregnancy rate (Table 2 ). Therefore, the primary outcome of this review was pregnancy rate, and live birth rate was analyzed when it was reported.

Subjects could have been pregnant at any time during treatment, and therefore treatment was stopped when human chorionic gonadotropin level increased. Thus, treatment duration was defined as the longest treatment in a given trial. Treatment duration in the included trials was at least 3 months except for that in the report by Yarali et al. (32) (Trial No.8 in Tables) which was only up to 6 weeks. Among the 10 included RCTs, the longest treatment duration was up to around 6 months in five trials (Trial No.1, 3, 4, 6, 9 in Tables) $(25,27,29-31$ ). There were only two trials with relevantly large sample sizes (>100 subjects) and sufficiently long treatment duration (6 months or 24 weeks) (Trial No.4, 6) $(27,29)$ (Table 1).

Among the 10 included RCTs, one study did not describe the random sequence generation method (29), four trials did not describe the allocation concealment method (24, 29, 31, 32). Only three RCTs had a low risk of blinding participants and personnel $(26,32,33)$, and Legro RS et al. could not use the blinding method due to lifestyle modification therapy (28). And because the outcome, clinical pregnancy rate, was not affected even without blinding method, all the ten studies had a low risk of outcome assessment. One study was rated high risk because of the high drop-out rate in the hCG group during follow-up (25) and three RCTs did not mention drop-out $(26,31,33)$. All ten studies reported appropriate outcomes. Three studies were considered to have a high risk of other bias due to the small sample size $(25,30,32)$, and one study was rated unclear risk because the sample size of the two groups was moderately different which were 33 in the metformin+CC group and 45 in the exenatide+CC group (31) (Figure 2).

\section{DISCUSSION}

\section{Improvement of IS After Treatment Increased Pregnancy Rate in Infertile PCOS Women Regardless of Nonsurgical Intervention}

Obesity is highly involved in the development of IR (34). To ensure consistency in our analyses, the included trials were analyzed by classifying body weight according to BMI at baseline.
Among RCTs that reported HOMA-IR, there were two in which mean BMI of groups was classified as overweight (Trial No.1, 2 in Tables) $(24,31)$, two where subjects were obese (Trial No.3, 4 in Tables) $(29,30)$, and two where subjects were severely obese (Trial No. 5, 6 in Tables) $(27,33)$. In all these trials, baseline HOMA-IR was not significantly different between groups in the same trial. In trials where subjects were overweight or obese, pregnancy rate increased in the group that had a significantly larger reduction of HOMA-IR after treatment $(24,29,31)$. Furthermore, if there were no significant differences in HOMA-IR between groups, there were no significant differences in pregnancy rate between groups (30). Agrawal et al. (24) (Trial No.2 in Tables) and Ortega-González et al. (30) (Trial No.3 in Tables) also reported live birth rate and arrived at the same conclusion as that for pregnancy rate. Regarding two other trials where subjects were severely obese, the same observation was made by El Sharkwy and Sharaf El-Din (33) (Trial No.5 in Tables), but not by Legro et al. (27) (Trial No.6 in Tables). In the trial by El El Sharkwy and Sharaf El-Din (33) (Trial No.5 in Tables), the group with the addition of L-carnitine to the combination of metformin and CC achieved a further reduction of HOMA-IR and higher clinical pregnancy rate (33). In the trial by Legro et al. (27) (Trial No.6 in Tables), the three groups were administered metformin monotherapy, CC monotherapy, or combined metformin plus CC. Treatments were provided for up to 6 months, and although none achieved reduction of HOMA-IR and even significantly increased in CC group, HOMA-IR in the combined therapy group was significantly lower than in the CC group. However, the significant difference in HOMA-IR was because of the increase in CC monotherapy group. Regarding pregnancy rate, there was no significant difference between the CC and CC plus metformin groups. However, the pregnancy rate in the metformin group was significantly lower than in the other two groups (26). In the trial by Legro et al. (27) (Trial No.6 in Tables), no treatments (CC alone, metformin alone, or combined CC plus metformin) achieved reduction of IR, which suggested pregnancy rate was more closely associated with the ovulationpromoting effect of CC. The explanation for why metformin failed to achieve improvement of IS in the trial may have been the severe obesity of subjects. However, more evidence is necessary to confirm this theory.

Therefore, these trials suggested pregnancy rate was increased in the groups with a larger reduction of HOMA-IR.

For parameters that reflect IS (FPG/INS ratio or insulin sensitivity index), three trials recruited overweight PCOS women (Trial No.7, 8, 9 in Tables) $(25,26,32)$, whereas one had severely obese subjects (Trial No.10 in Tables) (28). In overweight subjects, the pregnancy rate was significantly higher in the group where FPG/INS ratio was significantly higher compared with other groups in the same trial (26). Moreover, when IS did not differ significantly between groups, there was no difference in pregnancy rates $(25,32)$. In the trial by Legro et al. (Trial No.10 in Tables), subjects were severely obese and received lifestyle modification, oral contraceptive pills (OCPs), or combined therapy with lifestyle modification and OCPs for 16 
TABLE 2 | The pre- and post- BMl, insulin sensitivity parameters in the RCTs and pregnancy rate and live birth rate in the included RCTs.

\begin{tabular}{|c|c|c|c|c|c|c|c|c|c|c|c|c|c|}
\hline $\begin{array}{l}\text { Trial } \\
\text { No. }\end{array}$ & Study & Intervention Group & $\begin{array}{l}\text { BMI before } \\
\text { treatment }\end{array}$ & $\begin{array}{l}\text { BMI after } \\
\text { treatment }\end{array}$ & $\begin{array}{c}\text { Sigificant } \\
\text { change in BMI } \\
\text { among groups }\end{array}$ & $\begin{array}{l}\text { Parameter } \\
\text { of IS }\end{array}$ & $\begin{array}{l}\text { Parameter } \\
\text { of IS before } \\
\text { treatment }\end{array}$ & $\begin{array}{l}\text { Parameter } \\
\text { of IS after } \\
\text { treatment }^{1}\end{array}$ & $\begin{array}{c}\text { Significant } \\
\text { change of IS } \\
\text { among } \\
\text { groups }^{2}\end{array}$ & Pregnancy rate & $\begin{array}{l}\text { Significant changes } \\
\text { of Pregnancy rate } \\
\text { among groups }^{2}\end{array}$ & Live birth rate & $\begin{array}{l}\text { Significant change } \\
\text { in Live birth rate } \\
\text { among groups }^{2}\end{array}$ \\
\hline \multirow[t]{2}{*}{1} & \multirow[t]{2}{*}{$\begin{array}{l}\text { Wang et al. } \\
\text { (31) }\end{array}$} & Metf+CC (N=33) & $25.74 \pm 6.37$ & - & & \multirow[t]{2}{*}{ HOMA-IR } & $6.93 \pm 0.69$ & $5.79 \pm 0.58$ & \multirow[t]{2}{*}{ Y } & 9/33 (27.3\%) & \multirow[t]{2}{*}{ Y } & - & - \\
\hline & & Exenatide+CC (N=45) & $26.26 \pm 5.71$ & & & & $7.02 \pm 0.84$ & $5.23 \pm 0.7^{\star}$ & & 24/45 (57.6\%) & & & \multirow{3}{*}{$\bar{Y}$} \\
\hline \multirow[t]{2}{*}{2} & \multirow{2}{*}{$\begin{array}{l}\text { Agrawal } \\
\text { et al. (24) }\end{array}$} & Metformin+CC (N=60) & $27.38 \pm 3.92$ & $25.45 \pm 3.22^{*}$ & NS & \multirow[t]{2}{*}{ HOMA-IR } & $2.83 \pm 1.29$ & $1.62 \pm 0.59^{*}$ & \multirow[t]{2}{*}{ Y } & $20 / 60(33.3 \%)$ & \multirow[t]{2}{*}{$\mathrm{Y}$} & $16.60(26.67 \%)$ & \\
\hline & & $\begin{array}{l}\text { Metformin+MYO+CC } \\
(\mathrm{N}=60)\end{array}$ & $27.71 \pm 3.60$ & $25.77 \pm 3.48^{\star}$ & & & $2.78 \pm 1.6$ & $1.46 \pm 0.51^{*}$ & & 38/60 (63.3\%) & & $33 / 60$ (55\%) & \\
\hline \multirow[t]{2}{*}{3} & \multirow{2}{*}{$\begin{array}{l}\text { Ortega- } \\
\text { González } \\
\text { et al. (30) }\end{array}$} & Metformin (N=18) & $34.1 \pm 1.6$ & $32.9 \pm 1.7$ & Y & HOMA-IR & $7.21 \pm 0.52$ & $2.43 \pm 0.3$ & NS & 3/18 (16.6\%) & NS & 2/18 (11.1\%) & \multirow[t]{2}{*}{ NS } \\
\hline & & Pioglitazone ( $N=17)$ & $32.2 \pm 1.0$ & $34.0 \pm 1.2^{\star}$ & & \multirow{3}{*}{ HOMA-IR } & $7.03 \pm 0.28$ & $2.42 \pm 0.31$ & \multirow{3}{*}{ Y } & 5/17 (29.4\%) & \multirow{3}{*}{ Y } & 2/17 (11.8\%) & \\
\hline \multirow[t]{2}{*}{4} & \multirow{2}{*}{$\begin{array}{l}\text { Liu et al. } \\
\text { (29) }\end{array}$} & 24w Metf $(N=80)$ & $28.29 \pm 1.86$ & $27.2 \pm 1.8^{*}$ & Y & & $3.89 \pm 1.12$ & $3.30 \pm 1.00$ & & 15/80 (18.3\%) & & & - \\
\hline & & $\begin{array}{l}\text { 12w Exenatide switch } \\
\text { to } 12 \mathrm{w} \text { Metf }(\mathrm{N}=78)\end{array}$ & $29.16 \pm 3.11$ & $26.04 \pm 3.52^{*}$ & & & $4.21 \pm 1.89$ & $2.92 \pm 1.31$ & & $34 / 78(43.6 \%)$ & & - & - \\
\hline \multirow[t]{2}{*}{5} & \multirow{2}{*}{$\begin{array}{l}\text { El Sharkwy } \\
\text { and Sharaf } \\
\text { El-Din (33) }\end{array}$} & Metf+CC (N=136) & $34.4 \pm 3.4$ & $32.5 \pm 3.2^{*}$ & NS & \multirow[t]{2}{*}{ HOMA-IR } & $2.83 \pm 0.7$ & $2.22 \pm 0.34$ & \multirow[t]{2}{*}{ Y } & 9/136 (6.6\%) & \multirow[t]{2}{*}{ Y } & - & - \\
\hline & & $\begin{array}{l}\text { Metf+CC+L-carnitine } \\
(\mathrm{N}=138)\end{array}$ & $35.5 \pm 3.2$ & $32.2 \pm 4.1^{*}$ & & & $2.72 \pm 0.38$ & $1.8 \pm 0.43^{*}$ & & 39/138 (28.2\%) & & 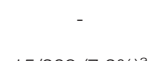 & - \\
\hline \multirow[t]{3}{*}{6} & \multirow[t]{3}{*}{$\begin{array}{l}\text { Legro et al. } \\
(27)\end{array}$} & Metformin (N=208) & $35.6 \pm 8.5$ & $-0.6 \pm 2.2$ & $Y$ (Metf vs CC) & \multirow[t]{3}{*}{$\begin{array}{l}\text { Change in } \\
\text { HOMA-IR }\end{array}$} & $5.6 \pm 8.9$ & $+(0.7 \pm 10.9)$ & \multirow{3}{*}{$\begin{array}{c}\text { Y (CC vs Metf } \\
+ \text { CC) } \\
\text { NS (Other } \\
\text { comparison }\end{array}$} & $18 / 208(8.7 \%)^{\mathrm{a}}$ & $\mathrm{Y}$ (Metf vs CC) & $15 / 208(7.2 \%)^{\mathrm{a}}$ & Y (Metf vs CC) \\
\hline & & $\mathrm{CC}(\mathrm{N}=209)$ & $36.0 \pm 8.9$ & $+0.2 \pm 1.6$ & $\begin{array}{l}Y(\text { Metf +CC vs } \\
\text { CC) }\end{array}$ & & $5.2 \pm 5.3$ & $+(2.2 \pm 12.6)$ & & 50/209 (23.9\%) $)^{b}$ & Y (Metf vs Metf+CC) & $\begin{array}{c}47 / 209 \\
(22.5 \%)^{\mathrm{b}}\end{array}$ & $Y$ (Metf vs Metf $+C C)$ \\
\hline & & Metformin+CC ( $N=209)$ & $34.2 \pm 8.4$ & $-0.5 \pm 1.4$ & $\begin{array}{l}\text { NS (Metf+CC vs } \\
\text { Metf) }\end{array}$ & & $5.6 \pm 10.2$ & - $(0.1 \pm 11.8)$ & & $65 / 209(31.1 \%)^{\mathrm{b}}$ & NS (CC vs Metf+CC) & $56 / 209(26.8)^{\mathrm{b}}$ & NS (CC vs Metf $+\mathrm{CC}$ ) \\
\hline 7 & $\begin{array}{l}\text { Karimzadeh } \\
\text { et al. (26) }\end{array}$ & Metformin $(\mathrm{N}=100)$ & $28.80 \pm 3.18$ & $28.45 \pm 2.8$ & NS & FPG/Insulin & $4.67 \pm 0.9$ & $6.07 \pm 1.4$ & Y & 40/100 (40.0\%) & Y & - & - \\
\hline & & Placebo ( $N=100)$ & $29.49 \pm 4.75$ & $29.29 \pm 4.8$ & & & $5.03 \pm 1.3$ & $5.05 \pm 1.3$ & & 11/100 (11.0\%) & & - & - \\
\hline 8 & $\begin{array}{l}\text { Yarali et al. } \\
\text { (32) }\end{array}$ & Metformin ( $(N=10)$ & $28.6 \pm 4.0$ & $28.0 \pm 3.4$ & NS & FPG/Insulin & $0.10 \pm 0.03$ & $0.12 \pm 0.07$ & NS & 3/10 (30.0\%) & NS & - & - \\
\hline & & Placebo ( $N=15)$ & $29.6 \pm 4.8$ & $29.8 \pm 4.9$ & & & $0.09 \pm 0.04$ & $0.10 \pm 0.06$ & & 1/15 (6.7\%) & & - & - \\
\hline 9 & $\begin{array}{l}\text { George } \\
\text { et al. (25) }\end{array}$ & Metf+CC $(\mathrm{N}=30)$ & $25.7 \pm 3.9$ & $24.9 \pm 2.9^{*}$ & Y & FPG/insulin & $11.7 \pm 12.8$ & $14.6 \pm 19.0$ & NS & $5 / 30(16.7 \%)$ & NS & & \\
\hline & & $\mathrm{hMG}(\mathrm{N}=30)$ & $25.9 \pm 2.9$ & $25.9 \pm 2.9$ & & & $4.8 \pm 2.7$ & $11.6 \pm 6.5^{\star}$ & & 7/30 (23.3\%) & & & \\
\hline 10 & $\begin{array}{l}\text { Legro et al. } \\
\text { (28) }\end{array}$ & $\begin{array}{l}\text { Lifestyle modification } \\
(\mathrm{N}=50)\end{array}$ & $35.1 \pm 4.6$ & & & $\begin{array}{l}\text { Insulin } \\
\text { sensitivity } \\
\text { index }\end{array}$ & $1.7(1.0,2.7)$ & $\begin{array}{c}+1.25(1.09 \\
-1.43)^{*}\end{array}$ & $\begin{array}{l}\text { Y(Lifestyle } \\
\text { modification vs } \\
\text { OCPs }\end{array}$ & 13/50 (26.0\%) & NS & 13/50 (26.0\%) & NS \\
\hline & & OCPs $(N=49)$ & $35.1 \pm 4.2$ & - & & & $2.0(1.4,2.6)$ & $\begin{array}{c}+0.89(0.77- \\
1.03)\end{array}$ & & $7 / 49(14.3 \%)$ & & $5 / 49(10.2 \%)$ & $\begin{array}{l}\text { When Merge Life } \\
\text { and combination }\end{array}$ \\
\hline & & Combination ( $N=50)$ & $35.5 \pm 4.4$ & - & & & $1.9(1.2,3.2)$ & $\begin{array}{c}+1.21(1.06 \\
-1.39)^{\star}\end{array}$ & $\begin{array}{l}\text { Y (Combination } \\
\text { vs OCPs) }\end{array}$ & 13/50 (26.0\%) & & 12/50 (24.0\%) & group, Y) \\
\hline
\end{tabular}

1, Mean $\pm S D$ or Mean change (95\% Cl); 2, The significant change reported in the RCTs.

*, The change after treatment was significant compared with that in baseline.

$Y$, The difference between groups was significant.

NS, Non-significant

+ , Value increased compared with baseline.

-, Value decreased compared with baseline.

$a, b$, the group with label a was significantly different from the group labeled $b$, and the same label means non-significant change between groups.

BMI, Body mass index; CC, clomiphene citreate; hMG, human menopausal gonadotropin; Metf, Metformin; MYO, myoinositol; OCPS, Oral contraceptive pills; HOMA-IR, homeostasis model assessment of insulin resistance; FPG, fasting plasma glucose; IS, Insulin sensitivity. 


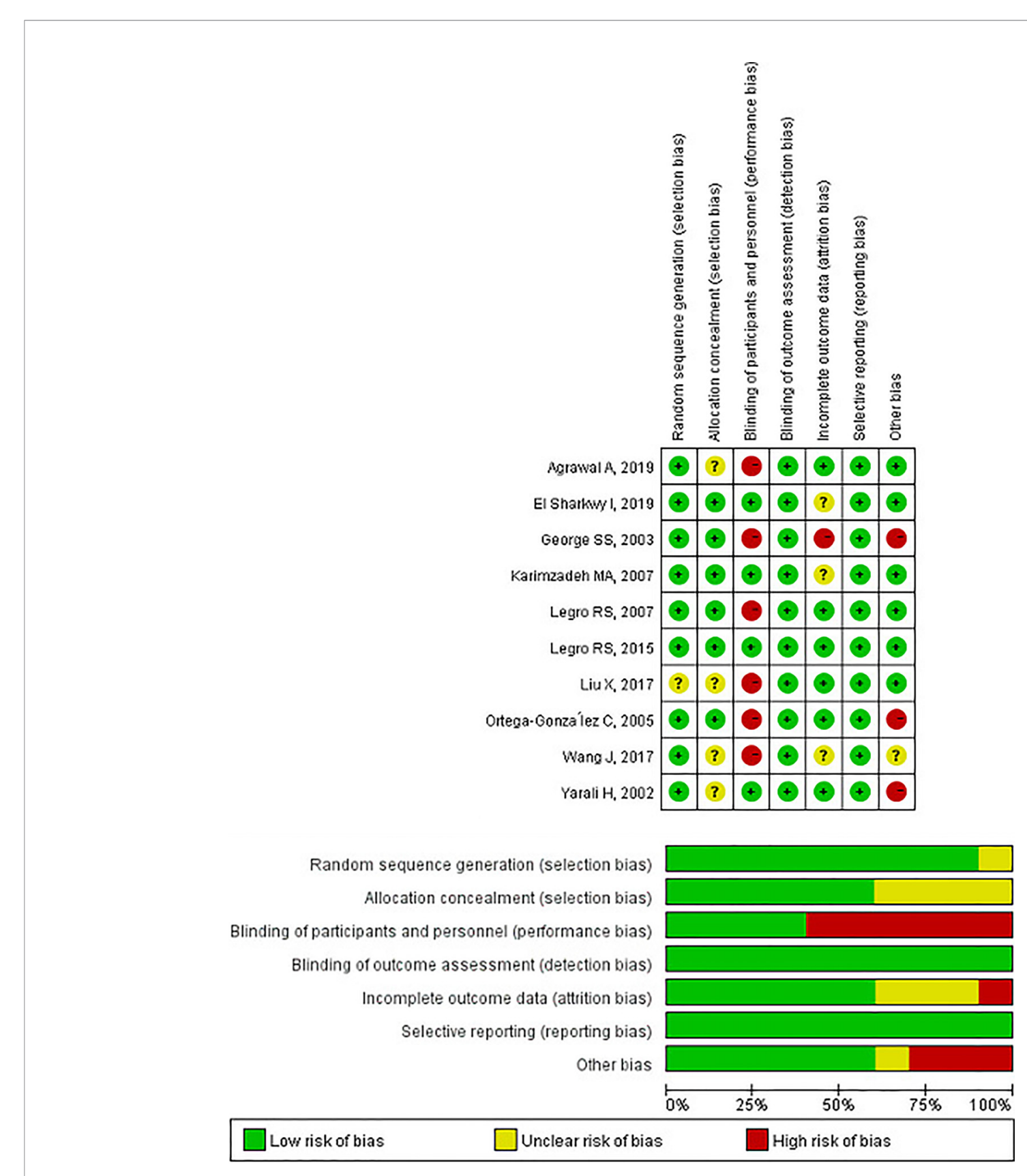

FIGURE 2 | The cochrane collaboration risk of bias evaluation for the included studies.

weeks (28). After treatment, insulin sensitivity index in the lifestyle modification and combined therapy groups was significantly increased and significantly higher than in the OCPs group. However, although pregnancy rate was not significantly different between the three groups, there was a trend toward a higher pregnancy rate in the lifestyle modification and combined therapy groups compared with the OCPs group. The authors believed this may have been because of the sample size. When they merged data from the lifestyle modification and combined therapy groups, they found the difference was significant between the merged and OCPs groups. This conclusion was also consistent with the previous discussion that pregnancy rate was increased in the groups with a larger improvement of IS. Live birth rate was reported by Legro et al. (28) (Trial No.10 in Tables), and the trend was the same as with pregnancy rate.

These results suggested pregnancy rate increased in the group with significant improvement of IS, even when the various parameters that reflect IS are considered.

All of these RCTs suggested achieving improvement of IS (including reduction of IR and increase of IS) after treatment is associated with increased pregnancy rate in infertile PCOS 
women, regardless of nonsurgical intervention. Furthermore, the benefit of post-treatment improvement of IS was more pronounced in women without severe obesity. For severely obese individuals, effective improvement of IS was difficult to achieve, which may have been because of inflammation and other issues caused by severe obesity.

\section{The Benefits of Improvement of IS was Inconsistent With the Reduction of BMI}

Obesity is one of the most important risk factors for IR. However, it appears that improvement of IS after treatment was not consistent with the change of BMI in infertile PCOS women. BMI did not change after treatment compared with that before treatment and was not significantly different between groups in the trials by Agrawal et al. (24) (Trial No.2 in Tables), El Sharkwy and Sharaf El-Din (33) (Trial No.5 in Tables), and Karimzadeh et al. (26) (Trial No.7 in Tables). However, HOMA-IR or FPG/INS ratio was significantly changed, and pregnancy rate was different between groups in the three RCTs $(24,26,33)$.

These data indicated that the reproductive benefit from the improvement of IS might be more important than that in the reduction of BMI.

\section{PCOS Women Without Significant Insulin Resistance at Baseline Also Benefit From the Improvement of IS}

To compare IS status in the different trials, significant IR was defined in this review as group mean HOMA-IR score $>3.0$, based on a large RCT where insulin resistance interventions after stroke were explored, and IR was identified as HOMA-IR score >3.0 (35). Although there are no globally standardized stratification criteria for the degree of IR, comparisons and analyses can aid in identifying evidence and trends regarding the effects of improvement of IS. HOMA-IR was reported in six studies, two of which included patients without IR (i.e., group mean HOMA-IR score <3.0) (Trial No.2, 5 in Tables). In the two studies, intervention groups achieved an improvement of IS, and the group with a larger reduction of HOMA-IR demonstrated a higher pregnancy rate.

This suggested improvement of IS can also increase pregnancy rate in PCOS women without IR. However, large, well-designed RCTs should be conducted to further validate this observation.

\section{Benefits of Improvement of IS on Reproductive Outcomes Occurred With Various Nonsurgical Interventions but Were Not Dependent on Insulin Sensitizers}

Two of the included RCTs evaluated the effect of metformin compared with placebo $(26,32)$. Treatment with metformin for 3 months in the trial by Karimzadeh et al. (26) (Trial No.7 in Tables) improved IS and increased pregnancy rate (26). This was consistent with the conclusion from a meta-analysis (13). However, 6-week metformin therapy in the trial by Yarali et al. (Trial No.8 in Tables) did not improve IS, and no difference was found between the metformin and placebo groups (32). This may have been because 6 weeks was too short to achieve significant improvement of IS.

Regarding combined therapy with metformin and CC, the metaanalysis did not find it was superior to CC monotherapy in PCOS infertile women, either in those with $\mathrm{BMI}<30.0$ or $\mathrm{BMI}>30.0$ (13). Similar observations were noted as part of this review. According to Legro et al. (27) (Trial No.6 in Tables), the combined therapy group demonstrated trends toward lower HOMA-IR and higher pregnancy rate compared with the CC monotherapy group, although they were not significant (28). This suggests the benefits of improvement of IS may be the secondary result of the potent effects of CC and other ovulation-inducing agents.

Other insulin sensitizers were also shown to effectively improve IS. Exenatide, a glucagon-like peptide-1 receptor agonist, was reported to reduce IR in type 2 diabetes patients (36). Compared with metformin, exenatide improved IS and pregnancy rate to a higher degree $(29,31)$. Wang et al. (31) (Trial No.1 in Tables) and Liu X et al. (29) (Trial No.4 in Tables) showed that exenatide improved IS and pregnancy rate, and the effect was superior to that of metformin, despite exenatide and metformin both being insulin-sensitizing agents. Pioglitazone, a typical insulin sensitizer, was proven superior to metformin at reducing IR $(37,38)$. However, other trials reported no difference between pioglitazone and metformin in improving IS in individuals with nonalcoholic fatty liver disease (39) or PCOS (40). Among the ten included RCTs, only one compared pioglitazone with metformin in PCOS infertile women, although no significant difference was found between the two groups (Trial No.3 in Tables) (30). However, this may have been because the sample size $(\mathrm{N}=47)$ was too small to demonstrate a statistical difference. More evidence is necessary to confirm the efficiency and safety of pioglitazone in PCOS women.

Adjuvant drugs, such as myoinositol (MYO) and L-carnitine, were not considered as traditional insulin-sensitizing agents but helped improve IS in PCOS women (Trial No.2, 5 in Tables) (24, 33). MYO is the precursor of inositol triphosphate, a second messenger that regulates thyroid-stimulating hormone, folliclestimulating hormone, and insulin (41). A previous study indicated that MYO has an effect on improving IS (42) and estradiol levels in PCOS women (43). Previous studies suggested L-carnitine can reduce IR and BMI in PCOS women $(44,45)$. However, additional high-quality RCTs are required to confirm the effect and safety of these drugs in infertile PCOS women.

Only one RCT (with a small sample size $(\mathrm{N}=149)$ and shortterm intervention) assessed the effect of lifestyle modification in infertile women with PCOS (Trial No.10 in Tables) (28). However, it was found that short-term lifestyle modification improved IS and increased pregnancy and live birth rates (28). Lifestyle modification may be among the most cost-efficient methods for significantly improving IS and reducing BMI, although clinical compliance is poor. All overweight or obese women should undergo lifestyle modification as a basic intervention.

To summarize, metformin and other related drugs, or lifestyle modification can increase pregnancy rate, but only if these interventions significantly improve IS. It appears exenatide had a better effect than metformin at increasing pregnancy rate and 
improving IS. Metformin has been proven safe and is nonteratogenic, but additional evidence is necessary to confirm the safety of other insulin sensitizers (46).

\section{Strengths and Limitation}

By screening and analyzing existing RCTs, improvement of IR following nonsurgical interventions was strongly correlated with increased pregnancy rate in infertile women with PCOS. Although only two RCTs, Liu et al. (29) and Legro et al. (27) (Trial No.4,6), had relevantly large sample sizes and sufficient treatment durations, the conclusion and analysis were consistent in the studies. They were able to determine that pregnancy rate increased in the groups that achieved an improvement of IS. Therefore, nonsurgical therapeutic strategies that result in superior improvement of IS may aid infertile PCOS women to increase their possibility of a successful pregnancy.

This review had limitations. Evidence demonstrated that IUGR, SGA, and history of family diabetes contributed to PCOS patients with IR, and these factors might also affect the effectiveness of treatment on improving insulin sensitivity. However, few trials concerned about the factors so that there was insufficient information that can be obtained and discussed in the review. More evidence is required to fill the gap. Besides, most RCTs that explored the reproductive effects of nonsurgical interventions in PCOS women did not report changes in IR. Therefore, only some of these studies were included in this review, and some had small sample sizes. High-quality and large sample size RCTs are needed to confirm the results discussed in the systemic review.

\section{CONCLUSION}

Among the various nonsurgical interventions, the benefit of improvement of IS appeared to be superior in PCOS women

\section{REFERENCES}

1. March WA, Moore VM, Willson KJ, Phillips DI, Norman RJ, Davies MJ. The prevalence of polycystic ovary syndrome in a community sample assessed under contrasting diagnostic criteria. Hum Reprod (2010) 25(2):544-51. doi: 10.1093/humrep/dep399

2. Nandi A, Chen Z, Patel R, Poretsky L. Polycystic ovary syndrome. Endocrinol Metab Clin North Am (2014) 43(1):123-47. doi: 10.1016/j.ecl.2013.10.003

3. Teede HJ, Misso ML, Costello MF, Dokras A, Laven J, Moran L, et al. Recommendations from the international evidence-based guideline for the assessment and management of polycystic ovary syndrome. Hum Reprod (2018) 33(9):1602-18. doi: 10.1093/humrep/dey256

4. Homburg R. Clomiphene citrate-end of an era? A mini-review. Hum Reprod (2005) 20(8):2043-51. doi: 10.1093/humrep/dei042

5. Dellapasqua S, Colleoni M. Letrozole. Expert Opin Drug Metab Toxicol (2010) 6(2):251-9. doi: 10.1517/17425250903540246

6. Buse JB, Wexler DJ, Tsapas A, Rossing P, Mingrone G, Mathieu C, et al. 2019 Update to: Management of Hyperglycemia in Type 2 Diabetes, 2018. A Consensus Report by the American Diabetes Association (ADA) and the European Association for the Study of Diabetes (EASD). Diabetes Care (2020) 43(2):487-93. doi: 10.2337/dci19-0066

7. Asrm Asrm Org Practice Committee of the American Society for Reproductive Medicine. Electronic Address and Medicine Practice Committee of the American Society for Reproductive, Role of metformin for ovulation induction in infertile without severe obesity. The benefit of improvement of IS appears to be more important than that in changes of BMI after treatment even the BMI is one of the most crucial factors for IS. And IS improvement also benefits PCOS women without IR at baseline. Metformin and other related drugs, and lifestyle modification, may also be capable of improving IS. It appears exenatide had a better effect than metformin at improving IS and increasing pregnancy rate. Although additional large, welldesigned RCTs are necessary to confirm the benefits, the review emphasized the importance of achieving IS improvement in infertile PCOS women treatment.

\section{DATA AVAILABILITY STATEMENT}

The original contributions presented in the study are included in the article/supplementary material. Further inquiries can be directed to the corresponding author.

\section{AUTHOR CONTRIBUTIONS}

YL provided the conception, searched the literature, participated in planning how to do the work, abstracting study details and writing the manuscript. JL participated in screening and abstracting study details, discussing and organized the main text and writing the manuscript. ZY provided the conception, set the inclusion/exclusion criteria, participated in discussing and organizing the main text and revised the manuscript. DL provided clinical advice during the whole work in the view of gynecology and obstetrics. JM screened the studies. NT planed the whole work and revised the manuscript. All authors contributed to the article and approved the submitted version.

patients with polycystic ovary syndrome (PCOS): a guideline. Fertil Steril (2017) 108(3):426-41. doi: 10.1016/j.fertnstert.2017.06.026

8. Tang T, Lord JM, Norman RJ, Yasmin E, Balen AH. Insulin-sensitising drugs (metformin, rosiglitazone, pioglitazone, D-chiro-inositol) for women with polycystic ovary syndrome, oligo amenorrhoea and subfertility. Cochrane Database Syst Rev (2012) 2012(5):CD003053. doi: 10.1002/14651858.CD003053.pub5

9. Siebert TI, Viola MI, Steyn DW, Kruger TF. Is metformin indicated as primary ovulation induction agent in women with PCOS? A systematic review and metaanalysis. Gynecol Obstet Invest (2012) 73(4):304-13. doi: 10.1159/000335253

10. Li W, Chen Q, Xie Y, Hu J, Yang S, Lin M. Prevalence and degree of insulin resistance in Chinese Han women with PCOS: Results from euglycemichyperinsulinemic clamps. Clin Endocrinol (Oxf) (2019) 90(1):138-44. doi: $10.1111 /$ cen. 13860

11. De Melo AS, Dias SV, Cavalli Rde C, Cardoso VC, Bettiol H, Barbieri MA, et al. Pathogenesis of polycystic ovary syndrome: multifactorial assessment from the foetal stage to menopause. Reproduction (2015) 150(1):R11-24. doi: 10.1530/REP-14-0499

12. Franks S, Stark J, Hardy K. Follicle dynamics and anovulation in polycystic ovary syndrome. Hum Reprod Update (2008) 14(4):367-78. doi: 10.1093/humupd/dmn015

13. Morley LC, Tang T, Yasmin E, Norman RJ, Balen AH. Insulin-sensitising drugs (metformin, rosiglitazone, pioglitazone, D-chiro-inositol) for women with polycystic ovary syndrome, oligo amenorrhoea and subfertility. Cochrane Database Syst Rev (2017) 11:CD003053. doi: 10.1002/14651858.CD003053.pub6

14. Ng EHY, Wat NMS, Ho PC. Effects of metformin on ovulation rate, hormonal and metabolic profiles in women with clomiphene-resistant polycystic ovaries: 
A randomized, double-blinded placebo-controlled trial. Hum Reprod (2001) 16(8):1625-31. doi: 10.1093/humrep/16.8.1625

15. Nemati M, Nemati S, Taheri AM, Heidari B. Comparison of metformin and $\mathrm{N}$-acetyl cysteine, as an adjuvant to clomiphene citrate, in clomipheneresistant women with polycystic ovary syndrome. J Gynecol Obstet Hum Reprod (2017) 46(7):579-85. doi: 10.1016/j.jogoh.2017.07.004

16. Qublan HS, Yannakoula EK, Al-Qudad MA, El-Uri FI. Dietary intervention versus metformin to improve the reproductive outcome in women with polycystic ovary syndrome. A prospective comparative study. Saudi Med J (2007) 28(11):1694-8.

17. Malkawi HY, Qublan HS, Hamaideh AH. Medical vs. surgical treatment for clomiphene citrate-resistant women with polycystic ovary syndrome. J Obstet Gynaecol: J Institute Obstet Gynaecol (2003) 23(3):289-93. doi: 10.1080/ 01443610310000100123

18. Weerakiet S, Sophonsritsuk A, Lertvikool S, Satirapot C, Leelaphiwat S, Jultanmas R. Randomized controlled trial of different doses of metformin for ovulation induction in infertile women with polycystic ovary syndrome. J Obstet Gynaecol Res (2011) 37(9):1229-37. doi: 10.1111/j.1447-0756.2010.01507.x

19. Kocak M, Caliskan E, Simsir C, Haberal A. Metformin therapy improves ovulatory rates, cervical scores, and pregnancy rates in clomiphene citrateresistant women with polycystic ovary syndrome. Fertil Steril (2002) 77 (1):101-6. doi: 10.1016/S0015-0282(01)02941-7

20. Vandermolen DT, Ratts VS, Evans WS, Stovall DW, Kauma SW, Nestler JE. Metformin increases the ovulatory rate and pregnancy rate from clomiphene citrate in patients with polycystic ovary syndrome who are resistant to clomiphene citrate alone. Fertil Steril (2001) 75(2):310-5. doi: 10.1016/ S0015-0282(00)01675-7

21. Zhang J, Si Q, Li J. Therapeutic effects of metformin and clomiphene in combination with lifestyle intervention on infertility in women with obese polycystic ovary syndrome. Pak J Med Sci (2017) 33(1):8-12. doi: 10.12669/pjms.331.11764

22. Garvey WT, Mechanick JI, Brett EM, Garber AJ, Hurley DL, Jastreboff AM, et al. Obesity Clinical Practice Guidelines Reviewers of The, American Association of Clinical Endocrinologists and American College of Endocrinology Comprehensive Clinical Practice Guidelines for Medical Care of Patients with Obesity. Endocr Pract (2016) 22 Suppl 3:1-203. doi: 10.4158/EP161365.GL

23. W. H. O Expert Consultation, Appropriate body-mass index for Asian populations and its implications for policy and intervention strategies. Lancet (2004) 363(9403):157-63. doi: 10.1016/S0140-6736(03)15268-3

24. Agrawal A, Mahey R, Kachhawa G, Khadgawat R, Vanamail P, Kriplani A. Comparison of metformin plus myoinositol vs metformin alone in PCOS women undergoing ovulation induction cycles: randomized controlled trial. Gynecol Endocrinol (2019) 35(6):511-4. doi: 10.1080/09513590.2018.1549656

25. George SS, George K, Irwin C, Job V, Selvakumar R, Jeyaseelan V, et al. Sequential treatment of metformin and clomiphene citrate in clomipheneresistant women with polycystic ovary syndrome: A randomized, controlled trial. Hum Reprod (2003) 18(2):299-304. doi: 10.1093/humrep/deg105

26. Karimzadeh MA, Eftekhar M, Taheripanah R, Tayebi N, Sakhavat L, Zare F. The effect of administration of metformin on lipid profile changes and insulin resistance in patients with polycystic ovary syndrome. Middle East Fertil Soc J (2007) 12(3):174-8.

27. Legro RS, Barnhart HX, Schlaff WD, Carr BR, Diamond MP, Carson SA, et al. Myers and Med Cooperative Multicenter Reprod, Clomiphene, metformin, or both for infertility in the polycystic ovary syndrome. New Engl J Med (2007) 356(6):551-66. doi: 10.1056/NEJMoa063971

28. Legro RS, Dodson WC, Kris-Etherton PM, Kunselman AR, Stetter CM, Williams NI, et al. Randomized Controlled Trial of Preconception Interventions in Infertile Women With Polycystic Ovary Syndrome. J Clin Endocrinol Metab (2015) 100(11):4048-58. doi: 10.1210/jc.2015-2778

29. Liu X, Zhang Y, Zheng SY, Lin R, Xie YJ, Chen H, et al. Efficacy of exenatide on weight loss, metabolic parameters and pregnancy in overweight/obese polycystic ovary syndrome. Clin Endocrinol (2017) 87(6):767-74. doi: 10.1111/cen.13454

30. Ortega-González C, Luna S, Hernández L, Crespo G, Aguayo P, Arteaga-Troncoso $\mathrm{G}$, et al. Responses of serum androgen and insulin resistance to metformin and pioglitazone in obese, insulin-resistant women with polycystic ovary syndrome. J Clin Endocrinol Metab (2005) 90(3):1360-5. doi: 10.1210/jc.2004-1965

31. Wang J, Ruan X, Jin F, Sun Y, Wang J. Effects of exenatide combined with clomifene citrate on insulin resistance and angiotensin II/Angiotensin-(1-7) in peripheral blood in patients with polycystic ovary syndrome. Biomed Res (India) (2017) 28(19):8406-11.

32. Yarali H, Yildiz BO, Demirol A, Zeyneloğlu HB, Yiğit N, Bükülmez O, et al. Co-administration of metformin during $\mathrm{rFSH}$ treatment in patients with clomiphene citrate-resistant polycystic ovarian syndrome: a prospective randomized trial. Hum Reprod (2002) 17(2):289-94. doi: 10.1093/humrep/ 17.2.289

33. El Sharkwy I, Sharaf El-Din M. 1-Carnitine plus metformin in clomipheneresistant obese PCOS women, reproductive and metabolic effects: a randomized clinical trial. Gynecol Endocrinol (2019) 35(8):701-5. doi: $10.1080 / 09513590.2019 .1576622$

34. Kahn SE, Hull RL, Utzschneider KM. Mechanisms linking obesity to insulin resistance and type 2 diabetes. Nature (2006) 444(7121):840-6. doi: 10.1038/ nature 05482

35. Inzucchi SE, Viscoli CM, Young LH, Furie KL, Gorman M, Lovejoy AM, et al. and Iris Trial Investigators, Pioglitazone Prevents Diabetes in Patients With Insulin Resistance and Cerebrovascular Disease. Diabetes Care (2016) 39 (10):1684-92. doi: 10.2337/dc16-0798

36. Derosa G, Maffioli P, Salvadeo SA, Ferrari I, Ragonesi PD, Querci F, et al. Exenatide versus glibenclamide in patients with diabetes. Diabetes Technol Ther (2010) 12(3):233-40. doi: 10.1089/dia.2009.0141

37. Erem C, Ozbas HM, Nuhoglu I, Deger O, Civan N, Ersoz HO. Comparison of effects of gliclazide, metformin and pioglitazone monotherapies on glycemic control and cardiovascular risk factors in patients with newly diagnosed uncontrolled type 2 diabetes mellitus. Exp Clin Endocrinol Diabetes (2014) 122 (5):295-302. doi: 10.1055/s-0034-1370989

38. Sangeeta S. Metformin and pioglitazone in polycystic ovarian syndrome: a comparative study. J Obstet Gynaecol India (2012) 62(5):551-6. doi: 10.1007/ s13224-012-0183-3

39. Razavizade M, Jamali R, Arj A, Matini SM, Moraveji A, Taherkhani E. The effect of pioglitazone and metformin on liver function tests, insulin resistance, and liver fat content in nonalcoholic Fatty liver disease: a randomized double blinded clinical trial. Hepat Mon (2013) 13(5):e9270. doi: 10.5812/hepatmon.9270

40. Sohrevardi SM, Nosouhi F, Hossein Khalilzade S, Kafaie P, Karimi-Zarchi M, Halvaei I, et al. Evaluating the effect of insulin sensitizers metformin and pioglitazone alone and in combination on women with polycystic ovary syndrome: An RCT. Int J Reprod BioMed (2016) 14(12):743-54. doi: 10.29252/ ijrm.14.12.743

41. Genazzani AD. Inositol as putative integrative treatment for PCOS. Reprod BioMed Online (2016) 33(6):770-80. doi: 10.1016/j.rbmo.2016.08.024

42. Fruzzetti F, Perini D, Russo M, Bucci F, Gadducci A. Comparison of two insulin sensitizers, metformin and myo-inositol, in women with polycystic ovary syndrome (PCOS). Gynecol Endocrinol (2017) 33(1):39-42. doi: $10.1080 / 09513590.2016 .1236078$

43. Zeng L, Yang K. Effectiveness of myoinositol for polycystic ovary syndrome: a systematic review and meta-analysis. Endocrine (2018) 59(1):30-8. doi: 10.1007/s12020-017-1442-y

44. Xu Y, Jiang W, Chen G, Zhu W, Ding W, Ge Z, et al. L-carnitine treatment of insulin resistance: A systematic review and meta-analysis. Adv Clin Exp Med (2017) 26(2):333-8. doi: 10.17219/acem/61609

45. Samimi M, Jamilian M, Ebrahimi FA, Rahimi M, Tajbakhsh B, Asemi Z. Oral carnitine supplementation reduces body weight and insulin resistance in women with polycystic ovary syndrome: a randomized, double-blind, placebo-controlled trial. Clin Endocrinol (Oxf) (2016) 84(6):851-7. doi: 10.1111/cen.13003

46. Feig DS, Briggs GG, Koren G. Oral antidiabetic agents in pregnancy and lactation: a paradigm shift? Ann Pharmacother (2007) 41(7):1174-80. doi: 10.1345/aph.1K045

Conflict of Interest: The authors declare that the research was conducted in the absence of any commercial or financial relationships that could be construed as a potential conflict of interest.

Copyright (c) $2021 \mathrm{Liu}, \mathrm{Li}, \mathrm{Yan}, \mathrm{Liu}, \mathrm{Ma}$ and Tong. This is an open-access article distributed under the terms of the Creative Commons Attribution License (CC BY). The use, distribution or reproduction in other forums is permitted, provided the original author(s) and the copyright owner(s) are credited and that the original publication in this journal is cited, in accordance with accepted academic practice. No use, distribution or reproduction is permitted which does not comply with these terms. 